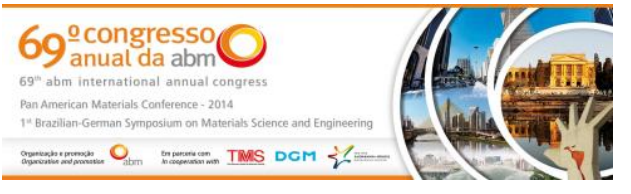

Tema: Gestão Sistêmica

\title{
REDUÇÃO DOS DESVIOS DE QUALIDADE POR MANCHAS SUPERFICIAIS (MS) NA FABRICAÇÃO DE FOLHAS DE FLANDRES NAS LINHAS DE ESTANHAMENTO 5 E 6*
}

Leandro José de Barros Cardoso ${ }^{1}$

\begin{abstract}
Resumo
A CSN possui 4 linhas de estanhamento eletrolítico (LEE) com capacidade de produção de 700 kt/ano de Folha de Flandres, nas quais durante o processo de estanhamento podem ocorrer desvios de qualidade que impactam no custo final do produto, afetando diretamente o custo de transformação da folha-de-flandres. Um destes desvios são as manchas superficiais (MS), caracterizadas por manchas na superfície do revestimento da Folha de Flandres que prejudicam o aspecto final do produto. O objetivo deste projeto foi reduzir o índice de desvio NOK por manchas superficiais das Linhas de Estanhamento 5 e 6 de 0,28\% para 0,14\% até abril de 2013. O projeto foi realizado utilizando a metodologia Lean Seis Sigma, obtida pela união do "Lean Manufacturing", que visa a eliminação de desperdícios durante o processo produtivo e o Seis Sigma como uma estratégia gerencial que busca a maximização do desempenho dos processos. A metodologia é dividida em cinco etapas: Define, Measure, Analyze, Improve e Control. Após a conclusão do projeto observamos uma redução de $65 \%$ no índice de desvio do defeito em relação à média do ano anterior (2012). Com esta redução obtivemos um ganho financeiro de $\mathrm{R} \$ 212.000,00$. Este projeto também serviu como projeto de Certificação de especialista Green Belt.
\end{abstract}

Palavras-chave: Estanhamento; Lean seis sigma.

\section{REDUCING QUALITY GAPS BY SURFACE STAINS ON TINPLATE PRODUCTIONS IN TINNING LINES 5 AND 6}

\section{Abstract}

CSN has 4 electrolytic tinning lines (ETL) with production capacity of $700 \mathrm{kt} / \mathrm{year}$ of tinplate, in which quality deviations that impact on the final cost of the product can occur during the tinning process, directly affecting the cost of transformation of tinplate. One of these defects are surface stains, characterized by stains on the surface of Tinplate coating that impair the final appearance of the product. The objective of this project was to reduce the NOK deviation index by surface stains of the tinning lines 5 and 6 from 0.28\% to 0.14\% until April 2013. The project was carried out using the Lean Six Sigma methodology, obtained by the union of "Lean Manufacturing", which aims to eliminate waste during manufacturing and Six Sigma as a management strategy that seeks to maximize the performance of processes. The methodology is divided into five steps: Define, Measure, Analyze, Improve and Control. Upon completion of the project we observed a $65 \%$ reduction in the rate of deviation of the defect relative to the average of the previous year (2012). With this reduction we achieved a financial gain of $R \$ 212.000 .00$. This project also served as a project for specialist Green Belt Certification.

Keywords: Tinning; Lean six sigma.

\section{Engenheiro Especialista, Estanhamento Eletrolítico, CSN, Volta Redonda, RJ, Brasil.}

\footnotetext{
* Contribuição técnica ao 69ำ Congresso Anual da ABM - Internacional e ao 14ํㅡㄹ ENEMET - Encontro Nacional de Estudantes de Engenharia Metalúrgica, de Materiais e de Minas, 21 a 25 de julho de 2014, São Paulo, SP, Brasil.
} 


\section{INTRODUÇÃO}

A CSN possui 4 linhas de estanhamento eletrolítico (LEE) com capacidade de produção de $700 \mathrm{kt} /$ ano de Folha de Flandres. Até 2007 todas utilizavam o Processo Ferrostan à base de ácido fenolsulfônico (PSA - phenol sulfonic acid). Atualmente observamos que os grandes fabricantes de Folhas de Flandres na Europa e EUA tem progressivamente abandonado a tecnologia Ferrostan e adotado o novo processo Ronastan, a base de ácido metanosulfônico (MSA - methane sulfonic acid) em suas linhas de produção [1].

A partir de 2007 a CSN iniciou um processo gradativo de conversão de todas suas linhas de produção para o processo a base de ácido metanosulfônico. Hoje todas as linhas de estanhamento eletrolítico da CSN estão utilizando o processo à base de MSA.

Com a mudança de tecnologia do processo, o mapeamento do processo (MP's) do estanhamento, os trabalhos de soluções de problemas (MSP's) de qualidade e as tabelas T ficaram desatualizados. Estas ferramentas são de grande importância para manutenção dos resultados de qualidade e produtividade das linhas de produção, pois são ferramentas bastante úteis para resolução dos problemas de qualidade do processo, além de serem utilizadas para o treinamento de novos funcionários.

Em função da conversão progressiva das LEE's e do tempo para sedimentação do conhecimento adquirido do novo processo, só foi possível iniciarmos a atualização dos trabalhos citados acima a partir de 2012.

Como metodologia para realização deste trabalho, foi escolhido o Lean Seis Sigma, obtida pela união do "Lean Manufacturing", que visa a eliminação de desperdícios durante o processo produtivo e o Seis Sigma como uma estratégia gerencial que busca a maximização do desempenho dos processos [2]. Para a questão dos desvios de qualidade focamos nas manchas superficiais (MS), caracterizadas por manchas na superfície do revestimento da Folha de Flandres que prejudicam o aspecto final do produto.

A metodologia Seis Sigma também pode ser vista como uma estratégia gerencial altamente disciplinada e que sempre busca quantificar os parâmetros avaliados. Como consequência, observamos um aumento expressivo do desempenho nos processos e aumento da lucratividade, através da melhoria da qualidade de produto [3].

Já o Lean Manufacturing, é uma metodologia que visa eliminar desperdícios, eliminando tudo aquilo que não gera valor e imprimir maior velocidade dentro dos processos de uma empresa. Como o Lean pode ser aplicado em todo tipo de trabalho, uma denominação mais apropriada é Lean Operations ou Lean Enterprise. As origens do Lean Manufacturing remontam ao sistema Toyota de Produção e está baseado na redução de sete tipos de desperdícios: defeitos (nos produtos), excesso de produção de mercadorias desnecessárias, estoques de mercadorias à espera de processamento ou consumo, processamento desnecessário, movimento desnecessário (de pessoas), transporte desnecessário (de mercadorias) e espera (dos funcionários pelo equipamento de processamento para finalizar o trabalho ou por uma atividade anterior) [4].

A integração entre o Seis Sigma e o Lean Manufacturing, através da junção de suas características principais, é chamado de Lean Seis Sigma, que por sua vez se mostra como uma metodologia mais abrangente, eficaz e adequada para a solução de todos os tipos de problemas relacionados à melhoria de processos e produtos.

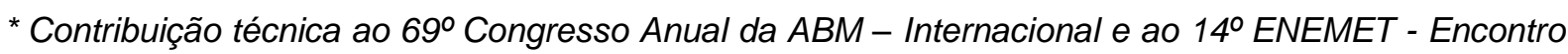
Nacional de Estudantes de Engenharia Metalúrgica, de Materiais e de Minas, 21 a 25 de julho de 2014, São Paulo, SP, Brasil.
} 


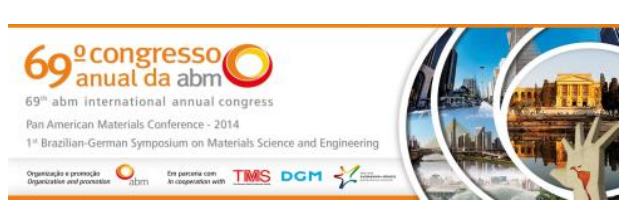

As manchas superficiais, tratadas neste projeto são o agrupamento de dois defeitos superficiais da folha de Flandres: a mancha de solução (MS) e a marca de rolo (MR). A mancha superficial é um defeito que prejudica o aspecto final da folha de Flandres, e por isso quando ocorre em intensidade de médio a forte deve ser desviada em função da classe de inspeção do material. Os desvios por MS e MR são inerentes ao processo de estanhamento, sendo por isso problemas históricos na Gerência de Estanhamento Eletrolítico [5].

O índice de desvios por esses defeitos sofreu um aumento considerável no ano de 2010, atingindo um índice de 0,34\% de desvio em relação às produções das LEE's 5 e 6, bem acima do observado no ano de 2011 que teve como média 0,25\%. Ao longo do primeiro semestre de 2012, foi observado que este se mantinha num patamar de $0,28 \%$ em relação à produção. Este valor correspondeu a $11 \%$ de todo 0 material desviado pelas LEE's 5 e 6 no período. As perdas ocasionadas por estes defeitos de qualidade afetaram diretamente no custo de transformação da folha de Flandres [6].

\subsection{Objetivo}

O projeto objetiva reduzir os desvios de qualidade por manchas superficiais nas Linhas de Estanhamento Eletrolítico 5 e 6 utilizando como metodologia e Lean Seis Sigma. Este projeto também foi utilizado para certificação do coordenador do projeto a "Especialista Green Belt".

\section{MATERIAIS E MÉTODOS}

A metodologia utilizada pelo Lean Seis Sigma para redução dos defeitos de qualidade é o DMAIC, onde cada letra representa uma etapa do processo:

Define (Definir), Measure (Medir)

Analyze (Analisar)

Improve (Melhorar)

Control (Controlar).

Neste projeto, cada etapa foi desenvolvida através de um Mapa de Raciocínio, onde cada questão era respondida com fatos e evidências das mesmas. Uma equipe multidisciplinar envolvendo profissionais das áreas de processo, manutenção e operação respondiam em conjunto às questões de cada etapa do mapa de raciocínio.

\subsection{Define}

Nesta etapa definimos o escopo do projeto com precisão e desenhamos o mapa do processo. Para tanto é preciso responder às seguintes questões:

- Qual é o problema?

Elevado índice de desvio de material devido a manchas superficiais (MS+MR) no $1^{\circ}$ semestre de 2012.

\footnotetext{
* Contribuição técnica ao $69^{\circ}$ Congresso Anual da ABM - Internacional e ao 14ํㅡㄹ ENEMET - Encontro Nacional de Estudantes de Engenharia Metalúrgica, de Materiais e de Minas, 21 a 25 de julho de 2014, São Paulo, SP, Brasil.
} 

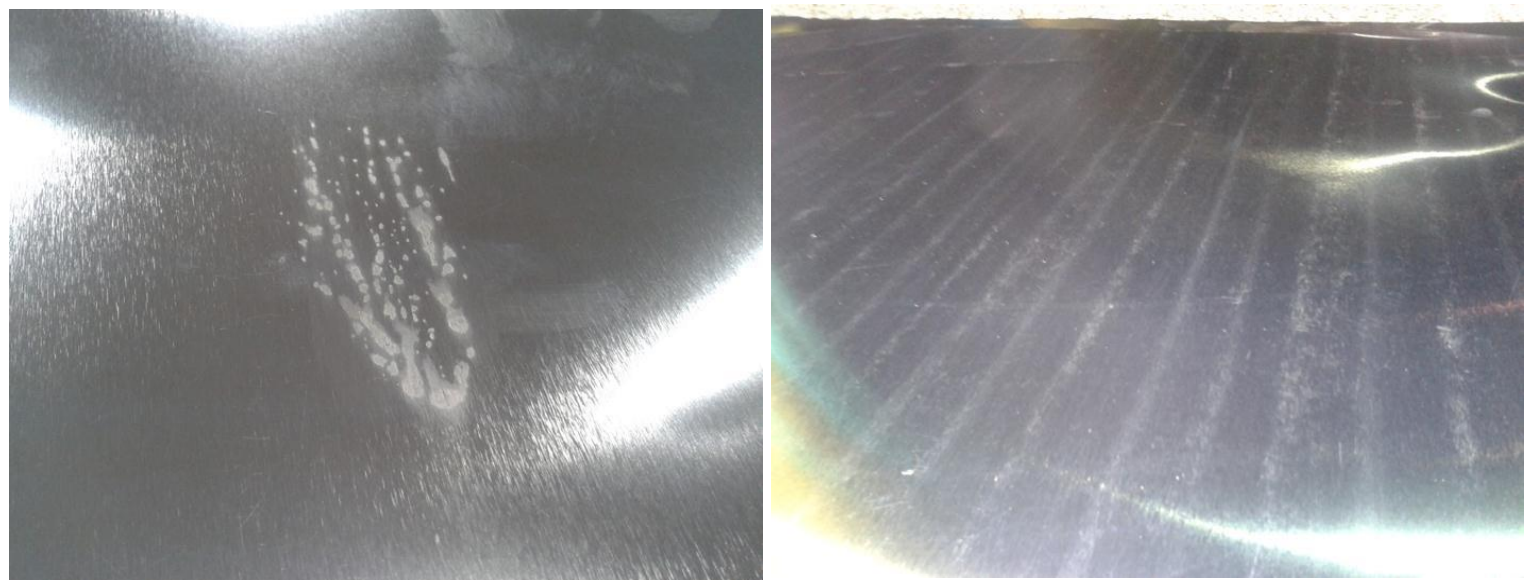

Figura 1. Manchas superficiais em amostras de folha de Flandres.

- Qual indicador será utilizado para medir o resultado do projeto? Índice de desvio NOK por manchas superficiais (IMS) por responsabilidade das LEE's 5 e 6

onde:

$$
\text { IMS }=(A / B) \times 100
$$

A - Desvio total NOK por manchas superficiais (MS+MR) por responsabilidade das LEE's 5 e 6 (t)

B - Produção total das LEE's 5 e 6 (t)

- Como o indicador vem se comportando historicamente?

Em 2010 tivemos o valor mais elevado desde 2007, 0,34\% de desvio. Em 2011 fechamos com a melhor média mensal, porém em 2012 estávamos com uma tendência de elevação do desvio. A média mensal verificada em junho $(0,31 \%)$ já se aproximava do valor mais elevado desde 2007.

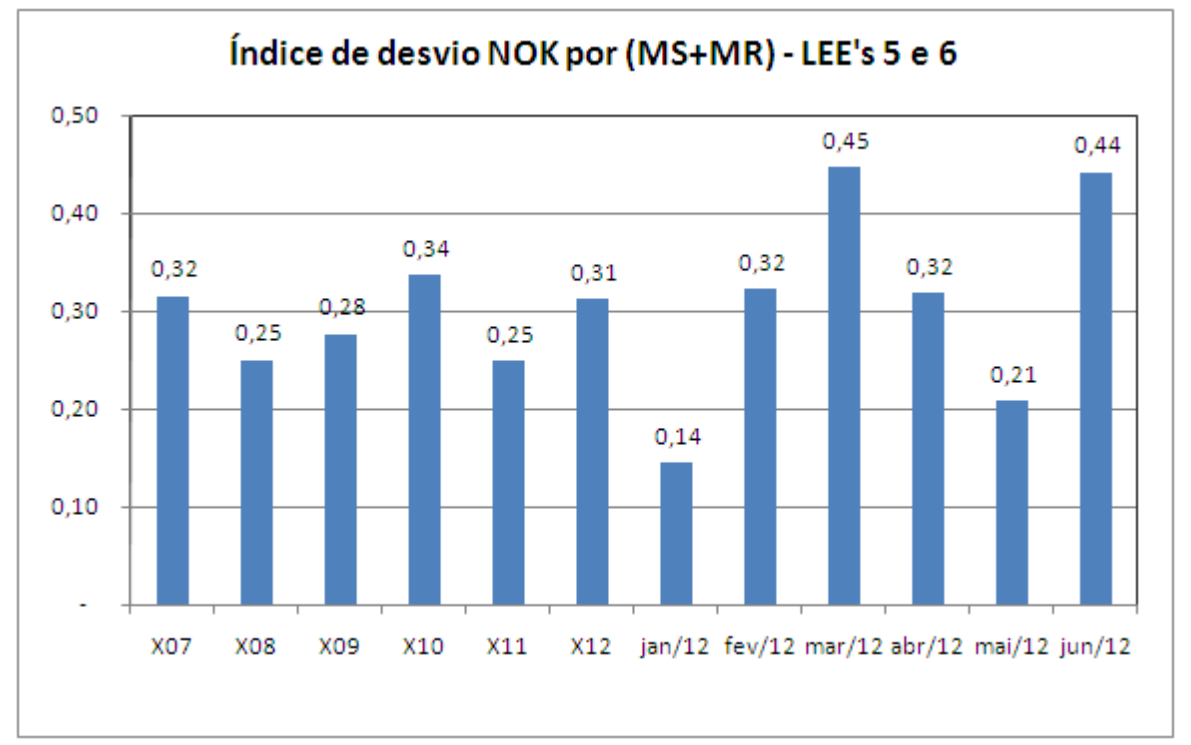

Figura 2. Índice de desvio NOK (\%) por manchas superficiais das LEE's 5 e 6.

- Qual é a Meta?

Reduzir o índice de desvio NOK por manchas superficiais (MS+MR) das LEE's 5 e 6 de $0,28 \%$ para $0,14 \%$ até abril de 2013 . Com base numa redução de $50 \%$ da média acumulada até setembro de 2012.

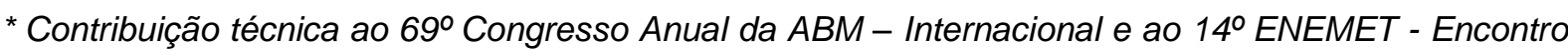
Nacional de Estudantes de Engenharia Metalúrgica, de Materiais e de Minas, 21 a 25 de julho de 2014, São Paulo, SP, Brasil.
} 


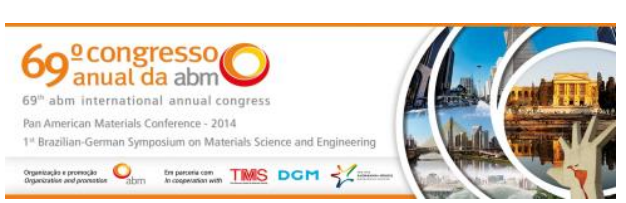

- Qual a visão dos clientes sobre o processo? Existem reclamações sobre o processo?

A mancha superficial (MS e MR) é um defeito que prejudica o aspecto final da folha de Flandres. Sua intensidade pode variar de leve a forte e a inspeção final do produto é visual. Desta forma, podem ocorrer liberações indevidas do problema para o Cliente final, e as mesmas podem gerar reclamações de qualidade.

- Quais as perdas resultantes do problema?

No período avaliado (1ำ semestre 2012), houve o desvio NOK de 554t, o sucateamento de 66 toneladas de material por (MS+MR) nas LEE's 5 e 6 e o reprocessamento de 643 t de material na Linha de Re-Inspeção (LCR).

Tabela 1. Perdas em toneladas de material desviado por manchas superficiais

\begin{tabular}{|c|c|c|c|c|c|}
\hline Mês & Produção & Desvio OK (t) & Desvio NOK (t) & Sucata $(\mathbf{t})$ & Total $(\mathbf{t})$ \\
\hline Janeiro & 33.854 & 68,0 & 40,4 & 8,4 & 48,8 \\
\hline Fevereiro & 31.692 & 140,2 & 94,5 & 7,5 & 102,0 \\
\hline Março & 34.236 & 132,9 & 136,7 & 16,2 & 152,9 \\
\hline Abril & 31.167 & 78,7 & 89,4 & 9,6 & 99,1 \\
\hline Maio & 34.655 & 84,8 & 61,1 & 11,2 & 72,3 \\
\hline Junho & 32.893 & 138,7 & 131,6 & 13,6 & 145,2 \\
\hline $\mathbf{2 0 1 2}$ & $\mathbf{1 9 8 . 4 9 6}$ & 643,3 & $\mathbf{5 5 3 , 8}$ & 66,4 & 620,2 \\
\hline
\end{tabular}

- Quais os ganhos potenciais do projeto?

Redução das perdas financeiras devido à:

- desvio de material da ordem de venda original para uma classe inferior;

- sucateamento de material;

- reprocessamento de material na linha de re-inspeção.

- Qual é o cronograma do projeto?

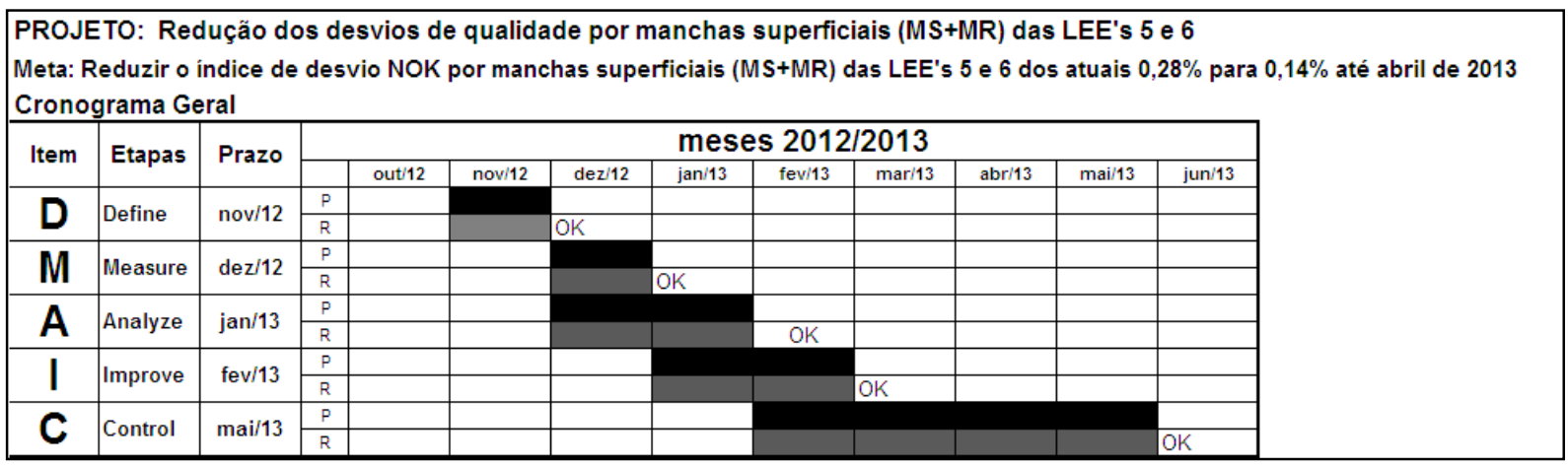

Figura 3. Cronograma de implantação do projeto.

\subsection{Measure}

Nesta etapa buscamos os dados atuais do processo, identificamos os problemas prioritários e determinamos 0 foco do problema. São feitos os seguintes questionamentos:

- Como o problema pode ser estratificado, isto é, quais os fatores de estratificação?

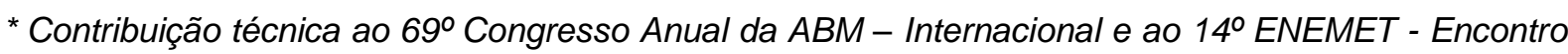
Nacional de Estudantes de Engenharia Metalúrgica, de Materiais e de Minas, 21 a 25 de julho de 2014, São Paulo, SP, Brasil.
} 


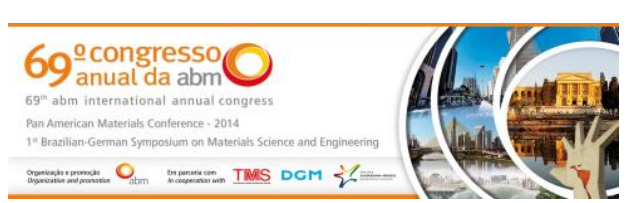

Devido a grande quantidade de "possíveis causas" levantadas e da complexidade entre as relações de causa e efeito, optamos por realizar analises utilizando a ferramenta "Árvore dos porquês", onde é possível definir com exatidão causas e efeitos que atuam no processo.

Abaixo listamos como exemplo duas árvores como exemplo. Ao todo, foram realizados 7 análises para cobrir todo o processo.

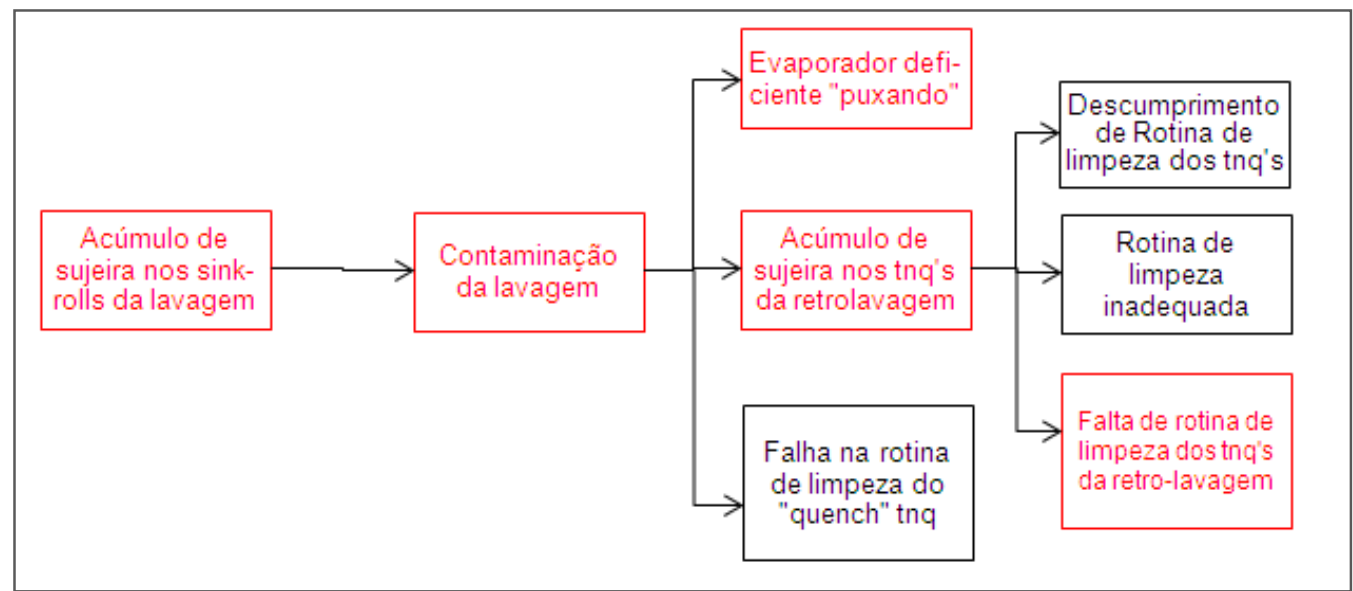

Figura 6. Diagrama de Árvore dos Porquês: Rolos submersos.

Verificado através da Arvore de Porquês que estas causas eram inter-relacionadas e que as causas fundamentais eram a falta de rotina de limpeza dos tanques da retrolavagem e Evaporador deficiente.

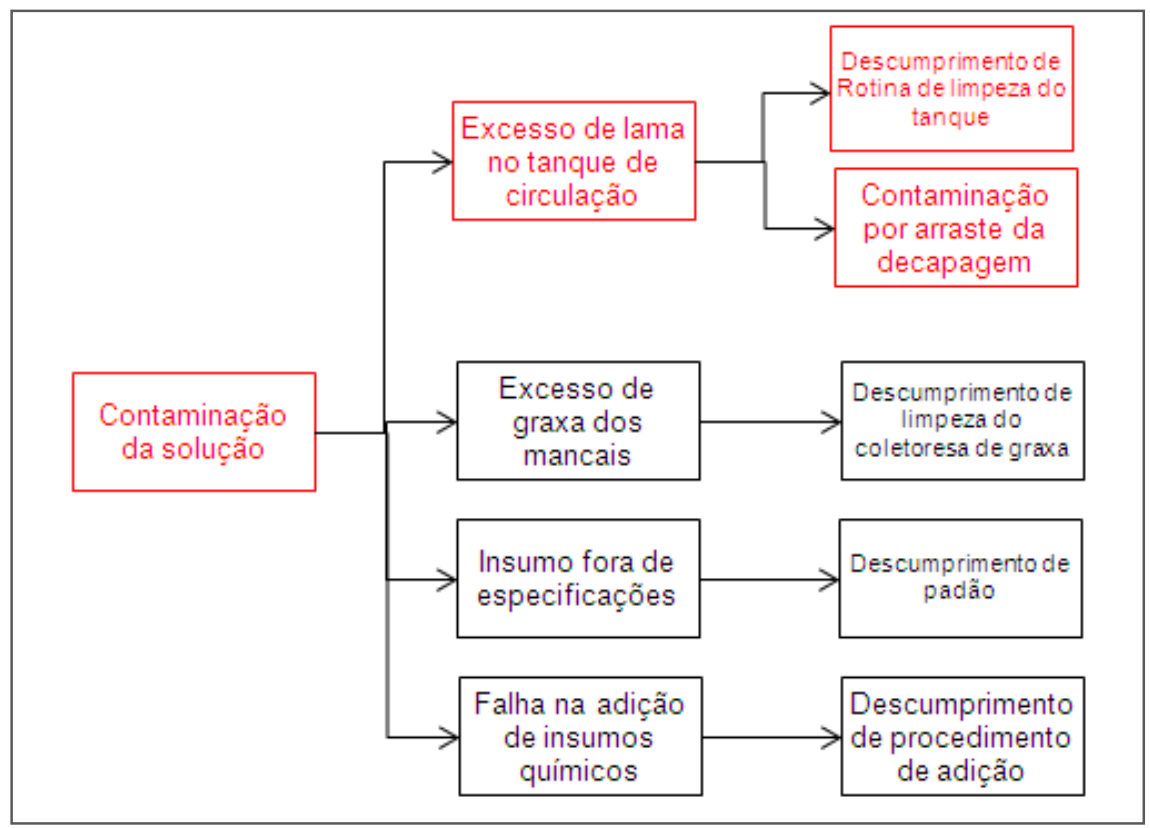

Figura 7. Diagrama de Árvore dos Porquês: contaminação da solução.

Verificado através da Arvore de Porquês que estas causas eram inter-relacionadas e que as causas fundamentais eram a contaminação por arraste da decapagem e o descumprimento da rotina de limpeza do tanque de circulação do plating.

\footnotetext{
* Contribuição técnica ao 69ำ Congresso Anual da ABM - Internacional e ao 14ํㅡㄹ ENEMET - Encontro Nacional de Estudantes de Engenharia Metalúrgica, de Materiais e de Minas, 21 a 25 de julho de 2014, São Paulo, SP, Brasil.
} 
- Será necessário revisar o mapa de processo?

Sim. Conforme análise das causas das ocorrências dos desvios, verificamos que o Mapeamento de Processo atual não contempla variáveis importantes para a controle do processo.

Por isso o Mapeamento de Processo foi revisado com foco na redução das Manchas Superficiais (MS e MR).

- As causas potenciais foram priorizadas?

As causas levantadas a partir do Brainstorming foram priorizadas utilizando a matriz GUT. As notas para a priorização foram feitas a partir das notas médias classificadas pelos integrantes do grupo. Previamente também ocorreu a eliminação de causas consideradas não influentes, baseada no conhecimento técnico do grupo.

Tabela 3. Tabela GUT (gravidade, urgência e tendência)

\begin{tabular}{l|c|c|c|c|c|}
\multicolumn{1}{c|}{ Causa } & Gravidade & Urgência & Tendência & GxUxT & Priorização \\
\hline sujeira no rolo & 4 & 5 & 4 & 80 & 1 \\
\hline passagem de solução & 5 & 4 & 4 & 80 & 1 \\
\hline rolo espremedor parando & 5 & 4 & 4 & 80 & 1 \\
\hline lavagem contaminada & 4 & 4 & 5 & 80 & 1 \\
\hline lama no tanque de retrolavagem & 4 & 5 & 4 & 80 & 1 \\
\hline acionamento/sincronismo de rolo submerso & 5 & 4 & 4 & 80 & 1 \\
\hline concentrações fora do padrão & 4 & 4 & 4 & 64 & 1 \\
\hline uso incorreto do sulfonic & 4 & 4 & 4 & 64 & 1 \\
\hline temperatura de processo fora do padrão & 4 & 4 & 4 & 64 & 1 \\
\hline vazẫo de soluçâao inadequada & 4 & 4 & 4 & 64 & 1 \\
\hline Evaporador "puxando" solução & 4 & 4 & 4 & 64 & 1 \\
\hline contaminação da solução & 4 & 4 & 3 & 48 & 2 \\
\hline alinhamento inadequado da cadeira & 4 & 3 & 4 & 48 & 2 \\
\hline esquema de ligação dos anodos da LA inadequada & 3 & 4 & 3 & 36 & 2 \\
\hline Condensado contaminado & 4 & 3 & 3 & 36 & 2 \\
\hline lavagem do TQ deficiente & 3 & 4 & 3 & 36 & 2 \\
\hline Superfície do rolo danificada & 3 & 3 & 3 & 27 & 3 \\
\hline anodo da LA sujo & 3 & 3 & 3 & 27 & 3 \\
\hline chuveiro lavagem entupido & 3 & 3 & 3 & 27 & 3 \\
\hline alinhamento do rolo & 3 & 2 & 4 & 24 & 3 \\
\hline revestimento/acabamento do rolo inadequado & 3 & 3 & 2 & 18 & 3 \\
\hline falta de inversão de polaridade & 3 & 3 & 3 \\
\hline refrigeração do rolo condutor & 3 & 2 & 3 & 18 & 3 \\
\hline pressão do rolo secador & 2 & 3 & 3 & 18 & 3 \\
\hline lama no tanque plating & 3 & 2 & 2 & 12 & 3 \\
\hline
\end{tabular}

- As causas fundamentais foram encontradas e comprovadas?

As causas fundamentais foram determinadas a partir das causas levantadas no Brainstorming. Estas foram relacionadas às observações feitas no acompanhamento e à FTA, onde verificamos as inter-relações causa-efeito.

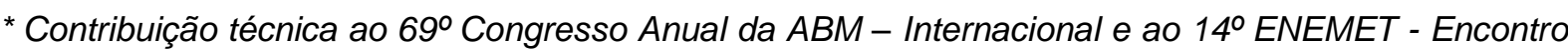
Nacional de Estudantes de Engenharia Metalúrgica, de Materiais e de Minas, 21 a 25 de julho de 2014, São Paulo, SP, Brasil.
} 


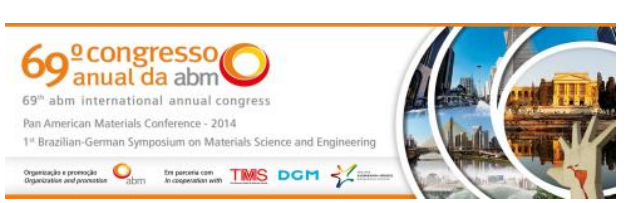

Tabela 4. Tabela com as causas fundamentais e suas descrições

\begin{tabular}{|c|c|c|c|c|c|c|}
\hline 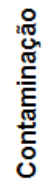 & 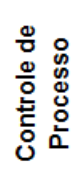 & 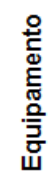 & 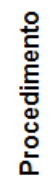 & $\stackrel{\circ}{ㅇ}$ & $\begin{array}{l}\text { CAUSA } \\
\text { FUNDAMENTAL }\end{array}$ & DESCRIÇÃO DA CAUSA \\
\hline$\times$ & & & & & Evaporador deficiente "puxando" solução & $\begin{array}{l}\text { Devido a uma deficência no evaporador, pode } \\
\text { ocorrer a contaminação do condensado com solução } \\
\text { do Plating. Esta contaminação irá ser levada para os } \\
\text { tanques de circulação da retrolavagem. }\end{array}$ \\
\hline$\times$ & & & & & $\begin{array}{l}\text { Falta de rotina de limpeza dos tnq's da } \\
\text { retro-lavagem }\end{array}$ & $\begin{array}{l}\text { Tanques de circulação da retrolavagem da limpeza } \\
\text { alcalina e decapagem com acúmulo de grande } \\
\text { quantidade de sujeira gerando uma lavagem } \\
\text { deficiente da tira, permitindo contaminação da } \\
\text { solução ou impregnação dos rolos. }\end{array}$ \\
\hline$\times$ & & & & & $\begin{array}{l}\text { Descumprimento de Rotina de limpeza } \\
\text { do tanque circulação plating }\end{array}$ & \multirow[t]{2}{*}{$\begin{array}{l}\text { O excesso de lama nos tanques de circulação do } \\
\text { plating promovem um aumento do nivel de } \\
\text { sedimentação da eletrólito. Este excesso de sólidos } \\
\text { em suspensão podem gerar defeitos de qualidade, } \\
\text { como manchas superficiais e densidades de } \\
\text { corrente. Este aumento de lama é gerado por um } \\
\text { descontrole nas concentrações de antioxidante e } \\
\text { sulfato da solução do plating. }\end{array}$} \\
\hline$\times$ & & & & & $\begin{array}{c}\text { Contaminação por arraste da } \\
\text { decapagem }\end{array}$ & \\
\hline \multirow[t]{9}{*}{$\times$} & & & & & $\begin{array}{l}\text { Lavagem da LA deficiente devido a } \\
\text { chuveiros entupidos }\end{array}$ & $\begin{array}{l}\text { Chuveiros entupidos prejudicam a limpeza da tira, } \\
\text { provocando a contaminação do processo } \\
\text { subsequente. }\end{array}$ \\
\hline & $\times$ & & & & $\begin{array}{c}\text { Falha operacional nas adições e controle } \\
\text { de processo }\end{array}$ & $\begin{array}{l}\text { Concentraç̃̃es fora da especificação do processo } \\
\text { sempre são causas potenciais de desvios de } \\
\text { qualidade, principalmente na: } \\
\text { - Limpeza alcalina abaixo do limite inferior causando } \\
\text { manchas por limpeza deficiente; } \\
\text { - Limpeza alcalina acima da especificação causando } \\
\text { contaminação da decapagem; } \\
\text { - Aditivo do plating muito alto gerando excesso de } \\
\text { espumo no platinf e aumento da sedimentação. } \\
\text { - Relação de Sn/acidez fora causando manchas ou } \\
\text { densidade de corrente, etc. }\end{array}$ \\
\hline & & $\times$ & & & $\begin{array}{l}\text { Retificador da LA deficiente não } \\
\text { invertendo polaridade automaticamente }\end{array}$ & $\begin{array}{l}\text { A falta de inversão de polaridade nos eletrodos da } \\
\text { limpeza alcalina promovem acúmulo de sujidade nos } \\
\text { eletrodos catódicos, levando a perda de eficiência de } \\
\text { limpeza da tira. }\end{array}$ \\
\hline & & & $\times$ & & $\begin{array}{l}\text { Falha operacional no ajuste da inversão } \\
\text { de polaridade provocando acúmulo de } \\
\text { sujidades nos anodos. }\end{array}$ & \multirow{2}{*}{$\begin{array}{l}\text { Anodos sujos geram uma deficiência de limpeza, } \\
\text { provocando manchas. }\end{array}$} \\
\hline & & $\times$ & & & $\begin{array}{l}\text { Descumprimento da rotina da limpeza e } \\
\text { troca dos eletrodos da limpeza alcalina }\end{array}$ & \\
\hline & & $\times$ & & & $\begin{array}{l}\text { esquema de ligação dos anodos da LA } \\
\text { inadequada }\end{array}$ & $\begin{array}{l}\text { Uma ligação incorreta dos dos eletrodos da limpeza } \\
\text { alcalina podem provocar manchas superficiais devido } \\
\text { a má limpeza do material. Independentemente do } \\
\text { minimo de corrente estar sendo aplicado. Para a } \\
\text { limpeza adequada, além da corrente mínima, os } \\
\text { passes anódicos e catódicos devem estar } \\
\text { distribuidos uniformente em ambas as faces da tira. }\end{array}$ \\
\hline & & & $\times$ & & alinhamento inadequado da cadeira & $\begin{array}{l}\text { Cadeira de espremedores com alinhamento } \\
\text { deficiente promovem desgaste acelerado e irregular } \\
\text { dos rolos. E os rolos com desgaste irregular } \\
\text { provocam manchas por passagem de solução, além } \\
\text { da mesma se acumular nos rolos subsequentes. }\end{array}$ \\
\hline & & & & $\times$ & superfície do rolo danificada & $\begin{array}{c}\text { Rolos com superfície danificada permitem passagem } \\
\text { de solução e acúmulo de sujeira nos rolos } \\
\text { subsequentes, o que pode gerar manchas de } \\
\text { solução. }\end{array}$ \\
\hline & & & & $\times$ & $\begin{array}{l}\text { acionamento/sincronismo de rolo } \\
\text { submerso }\end{array}$ & $\begin{array}{c}\text { Rolos submersos sem acionamento ou com } \\
\text { sincronismo deficiente imprimem marcas (dos frisos) } \\
\text { na superficie do material, devido ao acúmulo normal } \\
\text { de sujeira nestes frisos. }\end{array}$ \\
\hline
\end{tabular}

\footnotetext{
* Contribuição técnica ao 69ํㅡㄹ Congresso Anual da ABM - Internacional e ao 14ํㅡㄹ ENEMET - Encontro Nacional de Estudantes de Engenharia Metalúrgica, de Materiais e de Minas, 21 a 25 de julho de 2014, São Paulo, SP, Brasil.
} 


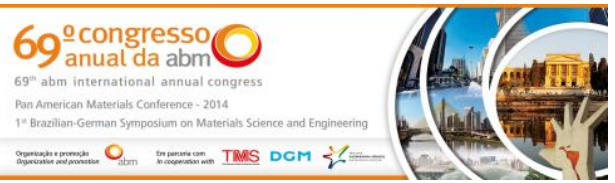

\section{RESULTADOS E DISCUSSÃO}

Os resultados, dentro do DMAIC são apresentados na etapa Improve e Control:

\subsection{Improve}

São feitas as análises das alternativas, elaborados os planos de ação, são também propostas as mudanças no processo.

- Quais as possíveis soluções?

As causas fundamentais foram divididas em focos principais e listadas as soluções adequadas para cada problema. Abaixo apresentamos um resumo do plano de ação executado.

Tabela 5. Tabela com as soluções priorizadas e suas descrições

\begin{tabular}{|c|c|c|c|c|c|c|c|}
\hline 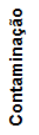 & 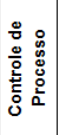 & 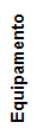 & 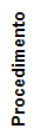 & $\stackrel{\circ}{\check{0}}$ & $\begin{array}{l}\text { CAUSA } \\
\text { FUNDAMENTAL }\end{array}$ & SOLUÇÕES PRIORIZADAS & Tipo de ação \\
\hline \multirow{3}{*}{$x$} & & & & & \multirow{3}{*}{ Evaporador deficiente "puxando" solução } & Restabelecimento do Evaporador da LEE\#5 & Restabelecer equipamento \\
\hline & & & & & & Alteração das condições de funcionamento do evaporador da LEE\#6 & Revisão dos parâmetros de Controle \\
\hline & & & & & & Confecção do padrão de operação dos Evaporadores das LEE's 5 e 6 & Padronização de atividade \\
\hline \multirow[t]{2}{*}{$x$} & & & & & \multirow{2}{*}{$\begin{array}{l}\text { Falta de rotina de limpeza dos tnq's da } \\
\text { retro-lavagem }\end{array}$} & $\begin{array}{l}\text { Determinar frequência adequada de rotina de limpeza dos tanques de } \\
\text { circulação }\end{array}$ & Revisão de procedimento \\
\hline & & & & & & Padronizar rotina de limpeza dos tanques da retrolavagem & Padronização de atividade \\
\hline$x$ & & & & & $\begin{array}{l}\text { Descumprimento de Rotina de limpeza } \\
\text { do tanque circulação plating }\end{array}$ & $\begin{array}{l}\text { Padronizar a rotina de limpeza dos tanques do plating no SIGMA como } \\
\text { item critico para a Qualidade }\end{array}$ & Padronização de atividade \\
\hline \multirow[t]{2}{*}{$x$} & & & & & \multirow[t]{2}{*}{$\begin{array}{l}\text { Contaminação por arraste da } \\
\text { decapagem }\end{array}$} & $\begin{array}{l}\text { Revisar procedimento de alinhamento dos rolos da cadeira de secagem } \\
\text { da decapagem. Ação descaracterizada. Procedimento atual atende. }\end{array}$ & NA \\
\hline & & & & & & \begin{tabular}{|l} 
Desenvolver novo método de análise de sulfato na solução do Plating \\
\end{tabular} & Estudo para melhoria \\
\hline \multirow[t]{9}{*}{$\times$} & & & & & $\begin{array}{l}\text { Lavagem da LA deficiente devido a } \\
\text { chuveiros entupidos }\end{array}$ & Restabelecer bicos e filtros dos chuveiros. & Restabelecer equipamento \\
\hline & $\times$ & & & & $\begin{array}{l}\text { Falha operacional nas adições e controle } \\
\text { de processo pelos Operadores }\end{array}$ & $\begin{array}{l}\text { Reciclagem nos procedimentos operacionais e padrões técnicos de } \\
\text { processo dos operadores lideres e de solução das LEE's } 5 \text { e } 6\end{array}$ & Treinamento \\
\hline & & $\times$ & & & $\begin{array}{l}\text { Retificador da LA deficiente não } \\
\text { invertendo polaridade automaticamente }\end{array}$ & $\begin{array}{l}\text { Restabelecer inversão automática de polaridade dos retificadores da LA } \\
\text { das LEE's } 5 \text { e } 6 \text {. }\end{array}$ & Restabelecer equipamento \\
\hline & & & $x$ & & $\begin{array}{l}\text { Falha operacional no ajuste da inversão } \\
\text { de polaridade provocando acúmulo de } \\
\text { sujidades nos anodos. }\end{array}$ & $\begin{array}{l}\text { Orientar operadores para inversão manual de polaridade durante } \\
\text { processamento de material Dupla redução }\end{array}$ & Treinamento \\
\hline & & & $\times$ & & $\begin{array}{l}\text { Descumprimento da rotina da limpeza e } \\
\text { troca dos eletrodos da limpeza alcalina }\end{array}$ & $\begin{array}{l}\text { Padronizar a rotina de troca e limpeza dos eletrodos da Limpeza Alcalina } \\
\text { no SIGMA como item critico para a Qualidade }\end{array}$ & Revisão de procedimento \\
\hline & & $x$ & & & $\begin{array}{l}\text { esquema de ligação dos anodos da LA } \\
\text { inadequada }\end{array}$ & $\begin{array}{l}\text { Padronizar ligação dos eletrodos da limpeza alcalina com balanceamento } \\
\text { da distribuição dos eletrodos catódicos e anódicos. }\end{array}$ & Revisão de Padrão Técnico \\
\hline & & & $x$ & & alinhamento inadequado da cadeira & $\begin{array}{l}\text { Revisar procedimento operacional de alinhamento da cadeira de secagem } \\
\text { do Fluxo. }\end{array}$ & Revisão de procedimento \\
\hline & & & & $x$ & superfície do rolo danificada & Avaliar causas fundamentais da baixa vida útil dos rolos secadores & Estudo para melhoria \\
\hline & & & & $\times$ & $\begin{array}{l}\text { acionamento/sincronismo de rolo } \\
\text { submerso }\end{array}$ & $\begin{array}{l}\text { Restabelecer acionamento dos rolos submersos e normalizar controle de } \\
\text { velocidade }\end{array}$ & Restabelecer equipamento \\
\hline
\end{tabular}

- Será necessário priorizar as soluções?

Não será necessário, pois grande parte das soluções possuem baixa complexidade e baixo custo. Os custos necessários para implementação das ações corretivas são compatíveis com o orçamento de manutenção das LEE's e serão realizados de acordo com o calendário de Manutenções Preventivas dos equipamentos.

- As soluções priorizadas apresentam algum risco?

As soluções não apresentam nenhum risco de implementação. Foram selecionadas:

- 16 ações corretivas focadas da seguinte forma:

- 03 padronizações de novas atividades operacionais;

- 04 ações de restabelecimento de equipamentos;

- 02 ações de revisão de padrões técnicos de processo;

- 04 ações de revisão de procedimentos operacionais;

- 02 ações de treinamento/reciclagem

- 02 estudos de melhoria de processo

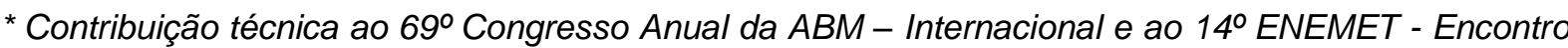
Nacional de Estudantes de Engenharia Metalúrgica, de Materiais e de Minas, 21 a 25 de julho de 2014, São Paulo, SP, Brasil.
} 


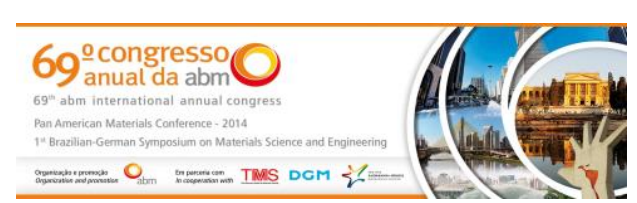

- As pessoas envolvidas com o cumprimento dos novos padrões foram treinadas?

Sim. Todos operadores foram treinados nas revisões dos padrões técnicos e procedimentos operacionais listados acima. Quanto às rotinas de manutenção, 0 Sistema de Gestão gera automaticamente as intervenções conforme programado.

- Como será o acompanhamento do processo com base no sistema de monitoramento (Plano de manutenção Corretiva e Preventiva)?

Foi elaborado fluxogramas de decisão baseados nos focos do problema e nas árvores de porquês.

Abaixo listamos o fluxograma OCAP (out of control action plan) geral que deve ser utilizado para controlar o índice de qualidade. A partir dele são selecionados os fluxogramas específicos para cada foco do problema.

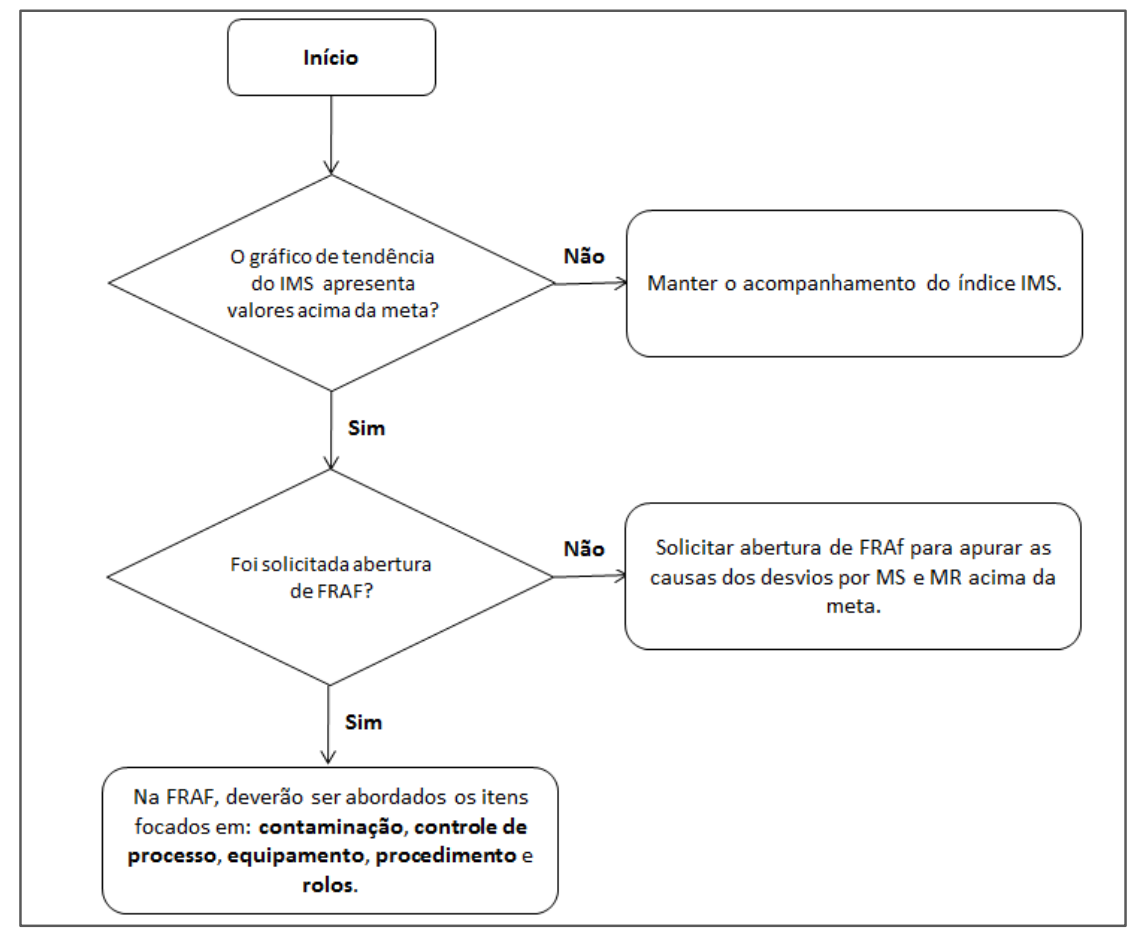

Figura 9. Fluxograma OCAP (out of control action plan) para acompanhamento do processo.

\section{CONCLUSÃo}

Observamos através do gráfico de acompanhamento do índice de desvio NOK por manchas superficiais (IMS) que após a implantação do projeto o mesmo sofreu uma redução considerável. Outro ponto a ressaltar é a questão da estabilidade, onde verificamos que o índice agora permanece num patamar sem grandes oscilações. Podemos inclusive dizer que este patamar de desvio é o esperado, uma vez o defeito de qualidade "manchas superficiais" é um defeito inerente ao processo de eletrodeposição de estanho.

Observamos uma melhoria significativa no conhecimento técnico da equipe no final da etapa de Análise. Isto, também foi um ganho considerável, pois em função do turn-over contínuo, parte do conhecimento técnico tem sido perdido. Verificamos que ao reunirmos uma equipe para analisar as causas de um determinado problema 0 conhecimento de todos aumenta e é multiplicado para os demais.

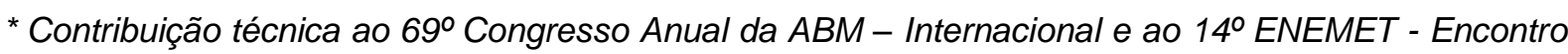
Nacional de Estudantes de Engenharia Metalúrgica, de Materiais e de Minas, 21 a 25 de julho de 2014, São Paulo, SP, Brasil. 
